\title{
Brain-Derived Neurotrophic Factor Serum Levels and Genotype: Association with Depression during Interferon- $\alpha$ Treatment
}

\author{
Francis E Lotrich*,', Salwa Albusaysi ${ }^{2}$ and Robert E Ferrell ${ }^{3}$ \\ 'Western Psychiatric Institute and Clinics, Department of Psychiatry, University of Pittsburgh Medical Center, Pittsburgh, PA, USA; \\ ${ }^{2}$ Department of Pharmaceutical Sciences, University of Pittsburgh, Pittsburgh, PA, USA; ${ }^{3}$ Department of Human Genetics, University of \\ Pittsburgh, Pittsburgh, PA, USA
}

\begin{abstract}
Depression has been associated with inflammation, and inflammation may both influence and interact with growth factors such as brainderived neurotrophic factor (BDNF). Both the functional Val66Met BDNF polymorphism (rs6265) and BDNF levels have been associated with depression. It is thus plausible that decreased BDNF could mediate and/or moderate cytokine-induced depression. We therefore prospectively employed the Beck Depression Inventory-II (BDI-II), the Hospital Anxiety and Depression Scale (HADS), and the Montgomery-Asberg Depression Rating Scale (MADRS) in 124 initially euthymic patients during treatment with interferon-alpha (IFN- $\alpha$ ), assessing serum BDNF and rs6265. Using mixed-effect repeated measures, lower pretreatment BDNF was associated with higher depression symptoms during IFN- $\alpha$ treatment $\left(F_{144,17.2}=6.8 ; P<0.000 I\right)$. However, although the Met allele was associated with lower BDNF levels $\left(F_{1,83.0}=5.0 ; P=0.03\right)$, it was only associated with increased MADRS scores $\left(F_{4,8.9}=20.3 ; P<0.00 \mathrm{I}\right)$, and not the BDI-II or HADS. An exploratory comparison of individual BDI-II items indicated that the Met allele was associated with suicidal ideation, sadness, and worthlessness, but not neurovegetative symptoms. Conversely, the serotonin transporter promoter polymorphism (5-HTTLPR) short allele was associated with neurovegetative symptoms such as insomnia, poor appetite and fatigue, but not sadness, worthlessness, or suicidal ideation. IFN- $\alpha$ therapy further lowered BDNF serum levels $\left(F_{4,37.7}=5.0 ; P=0.003\right)$, but this decrease occurred regardless of depression development. The findings thus do not support the hypothesis that decreasing BDNF is the primary pathway by which IFN- $\alpha$ worsens depression. Nonetheless, the results support the hypothesis that BDNF levels influence resiliency against developing inflammatory cytokine-associated depression, and specifically to a subset of symptoms distinct from those influenced by 5-HTTLPR. Neuropsychopharmacology (2013) 38, 985-995; doi: I0.1038/npp.2012.263; published online 16 January 2013
\end{abstract}

Keywords: cytokine; inflammation; growth factor; major depression; pharmacogenetic; psychoneuroimmunology

\section{INTRODUCTION}

Major depressive disorder (MDD) is a common and heterogeneous syndrome. When comorbid with other chronic diseases, the adverse health effects are worse than any other combination of chronic diseases without depression (Evans et al, 2005; Moussavi et al, 2007). There is accumulating evidence that inflammatory cytokines have the capacity to induce depressive symptoms (Maes, 2011; Miller et al, 2009), and several pathways have been identified by which peripheral cytokines can influence the central nervous system (Quan and Banks, 2007), prompting the hypothesis that many instances of depression may have

*Correspondence: Dr FE Lotrich, Western Psychiatric Institute and Clinics, Department of Psychiatry, University of Pittsburgh Medical Center, TDH Room 1504, 38 I I Ohara Street, Pittsburgh, PA I52 I3, USA, Tel: +4I2-246-6267, Fax: +4I2-246-6260,

E-mail: lotrichfe@upmc.edu

Received 7 September 2012; revised 30 November 2012; accepted 3 December 2012; accepted article preview online 18 December 2012 increased inflammatory cytokines as a critical element in their pathoetiology (Anisman, 2009; Dantzer et al, 2008; Lotrich, 2012; Raison et al, 2006). However, not every individual who is exposed to elevated inflammatory cytokines develops MDD, indicating a role for vulnerability and resiliency factors in moderating the adverse effects of inflammatory cytokines (Lotrich, 2011).

Iatrogenic MDD can be triggered by treatment with an exogenous inflammatory cytokine, interferon-alpha (IFN$\alpha$ ). This clinical situation has become a paradigmatic model for prospectively examining vulnerability/resilience to inflammatory cytokine-associated depression, as MDD develops in about $30 \%$ of non-depressed subjects within a few months of initiating IFN- $\alpha$ treatment (IFN-MDD) (Lotrich, 2009; Raison et al, 2005). A number of putative vulnerability factors for subsequent IFN-MDD have been identified ranging from a 'short' (S) low-expression allele in the promoter of the serotonin transporter (5-HTTLPR) (Bull et al, 2008; Lotrich et al, 2009), a polymorphism in the serotonin 1A receptor (Kraus et al, 2007), increased 
interleukin-6 (IL-6) serum levels and an IL-6 polymorphism (Bull et al, 2008; Prather et al, 2009), pre-existing poor sleep quality (Franzen et al, 2009), high neuroticism traits (Lotrich et al, 2007), increased hypothalamic-pituitaryadrenal axis sensitivity, (Raison et al, 2008), elevated ratio of omega-6 fatty acids to omega-3 fatty acids (Lotrich et al, 2012), and increased sensitivity to activating the p38 mitogen-activated protein kinase (Felger et al, 2011).

Accumulating evidence also supports an important role for decreased brain-derived neurotrophic factor (BDNF) activity in inflammatory cytokine-associated depression (Duman and Monteggia, 2006; Hashimoto, 2010; Kunugi et al, 2010; Numakawa et al, 2010). Inflammatory cytokines can decrease BDNF signaling (Cortese et al, 2011; Tong et al, 2008), as can lipopolysaccharide injections (Guan and Fang, 2006). Therefore, in addition to IFN- $\alpha$ 's effects on serotonin (Raison et al, 2009), dopamine (Felger et al, 2007), glutamate (Raison et al, 2010b), and the hypothalamic-pituitary-adrenal axis (Raison et al, 2010a), a decrease in BDNF may ultimately be the reason for the development of depression during IFN- $\alpha$ treatment. Related to this, social isolation decreases central BDNF, an effect which is likely mediated by the inflammatory cytokine IL$1 \beta$ (Barrientos et al, 2003; Ben Menachem-Zidon et al, 2008; Koo and Duman, 2008). IFN- $\alpha$ also appears to decrease cell proliferation in the hippocampus via increased IL- $1 \beta$ (Kaneko et al, 2006). In fact, the effects of both stress and inflammation may be mediated by impairments in growth factor function (Anisman, 2009; Koo et al, 2010; Peng et al, 2008). Moreover, many antidepressant effects likely occur through activation of BDNF's receptor (Saarelainen et al, 2003), and even the neuroprotective effect of a tricyclic antidepressant against lipopolysaccharide-induced apoptosis requires BDNF (Peng et al, 2008). In human bipolar populations, there is an inverse relationship between inflammatory cytokines and serum BDNF (Goldstein et al, 2011). Thus, it is feasible that cytokine-induced decreases in BDNF may result in the depressogenic effects of inflammatory cytokines such as IFN- $\alpha$.

Consistent with this, several studies have associated low serum BDNF with MDD (Aydemir et al, 2006; BocchioChiavetto et al, 2006; Gervasoni et al, 2005; Hashimoto, 2010; Sen et al, 2008; Shimizu et al, 2003; Verhagen et al, 2010), which subsequently normalizes with antidepressant treatment (Castren and Rantamaki, 2010; Chen et al, 2001). Also, a functional polymorphism causing a change from valine (Val) to methionine (Met) may result in diminished BDNF secretion (Egan et al, 2003). The Val to Met variant at amino acid 66 (Val66Met) results from a G758A polymorphism (rs6265) in BDNF's 11th exon. The Met allele has been associated with lower serum BDNF (Ozan et al, 2010), though this has not been consistently replicated (Duncan et al, 2009; Terracciano et al, 2010; Zhou et al, 2011). The Met allele has also been associated with increased suicide risk (Kanellopoulos et al, 2011; Pregelj et al, 2011; Sarchiapone et al, 2008), various depression-related traits (Beevers et al, 2009; Gatt et al, 2008; Gatt et al, 2010; Hayden et al, 2010; Jiang et al, 2005; Lau et al, 2010; Montag et al, 2010; Montag et al, 2008; Montag et al, 2009), and occasionally, a depression diagnosis (Aguilera et al, 2009; Borroni et al, 2009; Kim et al, 2008; Lavebratt et al, 2010). However, there are multiple studies in which this associa- tion with depression has not been replicated (Chen et al, 2008; Figueira et al, 2010; Middeldorp et al, 2010; Ribeiro et al, 2007; Suchanek et al, 2011; Wray et al, 2008).

There are therefore two potential non-mutually exclusive hypotheses that we examined. One is that IFN- $\alpha$ therapy decreases BDNF-but only in a subset of people who subsequently develop depression. That is, we examined whether decreased BDNF might mediate IFN- $\alpha$ 's depressogenic effect. The second hypothesis is that pre-existing low BDNF increases subsequent risk for developing depression. Prior adversity could have lasting epigenetic effects on BDNF production (Roth et al, 2009) as could the Met allele, resulting in increased vulnerability to depression. Thus, we determined whether low BDNF and/or the BDNF Met allele enhances (ie moderates) the depressogenic effect of IFN- $\alpha$.

Finally, different genetic regions have been associated with specific mood and anxiety traits in both mice (Henderson et al, 2004), and humans (Foley et al, 2003; Jang et al, 2004), which can affect genetic association study results (Lotrich, 2011). Consistent with this, we have found that polymorphisms affecting TNF- $\alpha$ and IL-28b are associated with specific mood-related symptom clusters in individuals receiving IFN- $\alpha$ (Lotrich et al, 2010; Lotrich et al, 2011). Also, we have found that a serotonin reuptake promoter polymorphism (5-HTTLPR) is associated with increased Beck Depression Inventory scores during IFN- $\alpha$ therapy (Lotrich et al, 2009), but another group did not find an association using the Hospital Anxiety Depression Scale (Kraus et al, 2007). Thus, we explored the possibility that either BDNF genotype and/or 5-HTTLPR may each influence a specific subset of depression symptoms.

\section{MATERIALS AND METHODS}

\section{Participants}

209 adult subjects with chronic HCV were screened using the Structured Clinical Interview for DSM-IV Axis I Disorders (SCID-IV), as previously described in an overlapping cohort of subjects (Lotrich et al, 2009; Prather et al, 2009), and as approved by the University of Pittsburgh Institutional Review Board. Anyone taking antidepressants, anticonvulsants, or antipsychotics was excluded (none were taking steroids, although most took non-steroidal antiinflammatory medications as needed for pain and fever during the course of IFN- $\alpha$ treatment). Those without active mood, anxiety, psychotic, or drug/alcohol abuse disorders were assessed for BDNF levels $(n=156)$. Of these, 124 provided blood for genotyping and subsequently started IFN- $\alpha$ treatment within 6 months-comprised weekly injections of pegylated IFN- $\alpha 2$ (PEG-IFN- $\alpha 2 \mathrm{a}$ : $135 \mu \mathrm{g} /$ week or PEG-IFN- $\alpha 2 \mathrm{~b}$ : 120 or $150 \mu \mathrm{g} /$ week) augmented with oral ribavirin. No subjects were noted to develop incident MDD during the period between the initial baseline assessment and the start of IFN- $\alpha$ therapy ( $56 \pm 55$ days).

\section{Depression Assessment}

Depression symptoms were assessed at baseline and then monthly during IFN- $\alpha$ treatment (for up to 4 months) using the Beck Depression Inventory-II (BDI-II) (Beck et al, 1988) 
Table I Baseline Characteristics of Subjects in this Study: Relationship with Either the Val/Met Polymorphism or Correlation with Baseline BDNF Levels

\begin{tabular}{lccc}
\hline & $\begin{array}{c}\text { Val/Met and } \\
\text { Met/Met }\end{array}$ & Val/Val & $\begin{array}{c}\text { Correlation } \\
\text { with BDNF }\end{array}$ \\
\hline Age (years) & $50.8 \pm 11.7$ & $47.1 \pm 11.5$ & $r=0.17 ; P=0.09$ \\
Gender (\% female) & $35 \%$ & $26.5 \%$ & $r=0.08 ; \mathrm{ns}$ \\
Race (\% Caucasian) & $87.8 \%$ & $87.4 \%$ & $r=0.06 ; \mathrm{ns}$ \\
Weight (kg) & $82.5 \pm 18.1$ & $86.6 \pm 16.5$ & $r=0.08 ; \mathrm{ns}$ \\
Sustained Viral Response & $47 \%$ & $45 \%$ & $r=0.2 ; P=0.1$ \\
History of MDD & $19.5 \%$ & $18.8 \%$ & $r=0.1 ; \mathrm{ns}$ \\
C-Reactive Protein (ng/ml) & $2.4 \pm 3.7$ & $1.9 \pm 2.3$ & $r=0.1 ; \mathrm{ns}$ \\
BDNF (ng/ml) & $17.0 \pm 10.5$ & $19.3 \pm 10.0$ & \\
CIRS-G & $4.5 \pm 2.4$ & $3.7 \pm 1.6$ & $r=0.1 ; \mathrm{ns}$ \\
BDI & $8.1 \pm 6.1$ & $8.6 \pm 9.0$ & $r=0.1 ; \mathrm{ns}$ \\
HADS & $8.0 \pm 5.7$ & $8.2 \pm 6.4$ & $r=0.1 ; \mathrm{ns}$ \\
MADRS & $3.4 \pm 4.0$ & $3.2 \pm 3.7$ & $r=0.06 ; \mathrm{ns}$ \\
PSQI & $6.9 \pm 4.2$ & $6.8 \pm 4.7$ & $r=0.01 ; \mathrm{ns}$ \\
AIAQ & $36.9 \pm 18.7$ & $37.2 \pm 20.2$ & $r=0.1 ; \mathrm{ns}$ \\
\hline
\end{tabular}

Prior to IFN- $\alpha$ treatment, the demographics, serum brain-derived neurotrophic factor (BDNF), Cumulative Illness Rating Scale-Geriatric (CIRS-G), Beck Depression Inventory (BDI-II), Hospital Anxiety and Depression Scale (HADS), Montgomery-Asberg Depression Rating Scale (MADRS), Pittsburgh Sleep Quality Index (PSQI), and Anger Irritability and Assault Questionnaire (AIAQ). There were no significant differences in these measures comparing those homozygous for the valine (Val) allele and those with a methionine (Met) allele. Subjects with lower BDNF levels trended towards being older and trended towards having a lesser chance of achieving a sustained clearance of their $\mathrm{HCV}$ infection - but otherwise there were no significant (ns, $p>0.15$ ) correlations ( $r$ ) at baseline.

as well as the Montgomery-Asberg Depression Rating Scale (MADRS) (Montgomery and Asberg, 1979) and Hospital Anxiety and Depression Scale (HADS) (Zigmond and Snaith, 1983). Several quantitative assessments, rather than a categorical outcome of MDD, were selected because of increasing evidence that many genetic vulnerabilities may be associated with specific symptom clusters during IFN- $\alpha$ therapy (Lotrich et al, 2010; Lotrich et al, 2011; Su et al, 2010). Subjects were given the opportunity to either mail in questionnaire results or complete them on routine clinic days. We did not observe an effect of date between last injection and date of questionnaire completion (ranging from 1 to 6 days) on depression symptomsconsistent with the very long half-life of pegylated IFN- $\alpha$ and serum levels that remain at a plateau during treatment (Jen et al, 2001).

However, participants who did develop DSM-IV defined MDD (SCID-IV assessed and confirmed by a psychiatrist) during the course of treatment-or where concerns about lethality arose-were typically started on an antidepressant. Moreover, if not already requested by the subject or their clinicians, an abbreviated SCID-IV interview that was focused specifically on mood disorders was employed at months 2 and 4. Data from individuals on antidepressant medications or no longer taking IFN- $\alpha$ are censored from the analyses.

\section{BDNF, CRP, and Polymorphism Assessment}

Blood samples were obtained between 1000 and 1600 hours, and serum (which does not contain platelets) was stored at -80C (between 5 and 60 months with no freeze-thaw cycles) until serum BDNF levels were measured using a highsensitivity $(<20 \mathrm{pg} / \mathrm{mL})$ and specific (no crossreactivity with other growth factors, except $13 \%$ crossreactivity with pro-BDNF) quantitative enzyme immunoassay (ELISA) (R\&D Systems, Minneapolis, MN). There was no relationship between storage time and BDNF measures. All samples were measured in duplicate and the average intra-assay and inter-assay coefficients of variation were $6.2 \%$ and $11.3 \%$, respectively. Of note, BDNF serum levels are not greatly associated with diurnal circadian rhythms (Choi et al, 2011) nor with platelet counts (Trajkovska et al, 2007). Serum CRP levels were determined using ELISA (Diaclone, Besancon, France) as previously described (Prather et al, 2009).

Genomic DNA isolated from lymphocytes (QuickGeneMini-80 kit; Fujifilm Life Science; www.autogen.com) was assessed using the 5'-nuclease Taqman assay (ABI 7900 DNA detection system), employing Assays-on-Demand and Assays-by-Design (Applied Biosystems, Foster City, CA) with $>95 \%$ accuracy. Although the BDNF polymorphism was in Harvey-Weinberg equilibrium, only three subjects were homozygous for Met/Met, which were therefore combined with the $38 \mathrm{Met} / \mathrm{Val}$ heterozygotes. Val/Val homozygotes were thus compared with any subject carrying the 'lower secreted' Met allele. The serotonin transporter length polymorphic region (5-HTTLPR), including the G/A variant in the Long allele, was determined as previously described (Lotrich et al, 2009), and Long/Long (La/La) homozygotes were compared with any subjects carrying either low expressing polymorphism (the Short (S) or the Lg allele).

\section{Statistical Analyses}

All statistics employed SPSS 18.0, and results are reported as mean $\pm S D$, and in graphs as mean \pm SE of the mean. Repeated-measure mixed-effect analyses, robust to randomly missing data (many subjects did not complete all assessments at all time points), were used to compare symptom changes over time. For these mixed-effect models, we first examined repeated covariance structures and selected analyses that provided the smallest Aikake Information Criteria (typically this was an unstructured covariance).

\section{RESULTS}

As seen in Table 1, subjects in this study were primarily middle aged (but ranged from 18 to 72 years), about $2 / 3$ were male and mostly Caucasian, and almost $20 \%$ had a prior history of MDD in remission but with some sleep quality problems. All subjects starting IFN- $\alpha$ therapy had a Cumulative Illness Rating Scale-Geriatric (CIRS-G) (Miller et al, 1992) score of at least 2 (because of HCV infection). Most subjects had only a few other medical problems diagnosed and treated such as hypertension and hyperlipidemia (eg, $<2 \%$ were being treated with statins) and $64 \%$ had CIRS-G scores of $\leqslant 4$. There was a trend for older 
subjects to have lower BDNF levels but other demographics were not correlated with BDNF levels (Table 1). Unless stated otherwise, we therefore did not include these variables as covariates in the analyses below.

Lower baseline BDNF was associated with increasing BDIII symptoms over time during IFN- $\alpha$ therapy $\left(\mathrm{F}_{144,17.2}=6.8\right.$; $P<0.0001)$. This supports the hypothesis that baseline BDNF may be inversely related to subsequent depression vulnerability. We next included baseline BDI-II as a covariate because of its known association with subsequent depression risk. The association between BDNF and subsequent BDI-II over time was still significant $\left(\mathrm{F}_{118,17.4}\right.$ $=2.0 ; P=0.05$ ). Likewise, when we covaried for baseline PSQI because of its known strong association with subsequent depression (Franzen et al, 2009; Prather et al, 2009), BDNF continued to be predictive of increased depression symptoms $\quad\left(\mathrm{F}_{97,20.9}=3.7 ; \quad P=0.001\right)$. Thus, neither baseline BDI-II nor PSQI mediates the relationship between BDNF and depression risk during IFN- $\alpha$ therapy.

To better characterize and illustrate these findings, we divided baseline BDNF levels by a median split (below or above $17 \mathrm{ng} / \mathrm{ml}$ ). Compared with higher baseline BDNF levels, lower baseline levels (BDNF $<17 \mathrm{ng} / \mathrm{ml}$ ) were associated with higher BDI-II scores $\left(\mathrm{F}_{1,98.9}=4.7\right.$; $P=0.03)$ as well as MADRS $\left(\mathrm{F}_{1,138.1}=4.2 ; P=0.04\right)$ and HADS scores $\left(\mathrm{F}_{1,187.0}=5.9 ; P=0.02\right)$ (Figure 1$)$ though the interaction with time for these three questionnaires was lost $\left(\mathrm{F}_{4,89.7}=1.1 ; P=0.3 ; \mathrm{F}_{4,198.5}=0.6 ; P=0.7 ; \mathrm{F}_{4,200.6}=1.3 ;\right.$ $P=0.3$, respectively). However, when covarying for baseline BDI-II, dichotomized baseline BDNF was associated with increasing MADRS and BDI-II scores over time $\left(\mathrm{F}_{4,46.2}=2.7 ; P=0.04\right)$. These prospective results are consistent with BDNF levels being a moderator of subsequent vulnerability to depression.

During IFN- $\alpha$ treatment, serum BDNF levels lessened over time in most subjects $\left(\mathrm{F}_{4,37.7}=5.0 ; P=0.003\right)$ (Figure 2). Nonetheless, BDNF levels went down similarly in the subjects who developed MDD and in those who completed treatment $\left(\mathrm{F}_{4,47.7}=0.6 ; \quad P=0.6\right) \quad$ (Figure 2). Therefore, although IFN- $\alpha$ treatment appears to decrease BDNF, these findings do not support the hypothesis that simply decreasing peripheral BDNF during IFN- $\alpha$ therapy is necessarily associated with the emergence of depression. However, as seen in Figure 2, those developing MDD started and ended with somewhat lower BDNF levels. Thus, we specifically examined the lowest BDNF level during IFN- $\alpha$ treatment for a subject ('BDNF nadir'), and found that those who ultimately developed MDD had the lowest BDNF nadir $(9.6 \pm 00.8 \mathrm{ng} / \mathrm{ml}) v s$ the other subjects $(14.0 \pm 1.2 \mathrm{ng} / \mathrm{ml}$; $P=0.001)$; and the area under the curve (AUC) in a receiver operating curve (ROC) for 'lowest BDNF' being associated with depression was 0.69 . This is similar in effect size to the prediction of MDD by baseline BDI-II scores, where the $\mathrm{AUC}=0.67$.

It is therefore possible that low BDNF nadirs achieved during treatment could be responsible for the development of depression. However, pretreatment BDNF was strongly associated with the BDNF nadir $(\mathrm{r}=0.57 \quad P<0.0001)$. Moreover, although pretreatment BDNF was associated with depression during IFN- $\alpha$ therapy as noted above, the 'BDNF nadir' was not statistically associated with increasing depression symptoms (eg, for MADRS, $\mathrm{F}_{60,13.1}=1.7$;
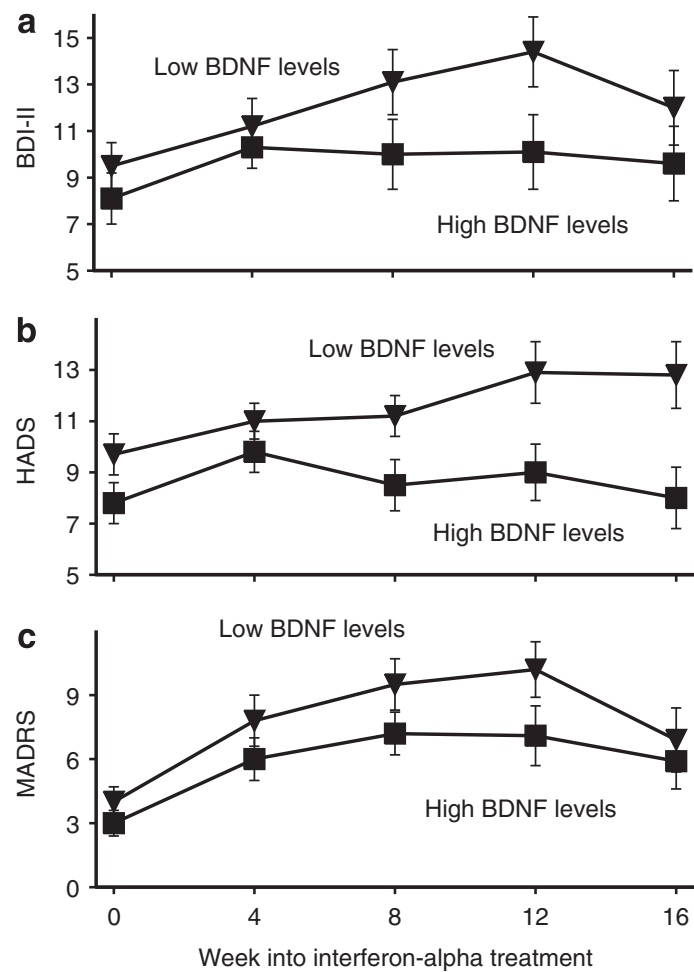

Figure I Subjects with below the median BDNF levels $(<17 \mathrm{ng} / \mathrm{ml})$ demonstrate elevated BDI-II (a), MADRS (b) and HADS (c) scores during IFN- $\alpha$ therapy.

$P=0.15)$. This later finding further weakens the hypothesis that BDNF mediates rather than moderates the depressive effects of IFN- $\alpha$ therapy - though the mediation hypothesis is not completely ruled out.

Throughout IFN- $\alpha$ treatment, those with the Val/Val genotype had higher BDNF levels than subjects carrying the Met allele $\left(\mathrm{F}_{1,83.0}=5.0 ; P=0.03\right)$, but BDNF levels went down similarly in both genetic groups $\left(\mathrm{F}_{4,42.9}=0.3 ; P=0.9\right)$ (Figure 2). Consistent with the findings above, the BDNF Met allele was associated with increased MADRS scores over time $\left(\mathrm{F}_{4,8.9}=20.3 ; P<0.001\right)$ - even when covarying for baseline BDI-II $\left(\mathrm{F}_{4,10.2}=20.0 ; P<0.001\right)$. As baseline BDNF was also associated with increased MADRS scores over time, we next covaried for baseline BDNF to examine whether low BDNF might mediate the relationship between the Met allele and increased MADRS scores-and the Met allele was no longer associated with increased MADRS over time $\left(\mathrm{F}_{4,24.7}=1.9 ; \quad P=0.14\right)$. This suggests that lower BDNF levels potentially mediate the genetic effect of the Met allele on depression risk.

Despite these findings using MADRS, the Val/Met genotype was not associated with total BDI-II $\left(\mathrm{F}_{4,32.4}=0.7\right.$; $P=0.6)$ nor the total HADS score $\left(\mathrm{F}_{4,30.5}=0.7 ; P=0.6\right)$ during IFN- $\alpha$ therapy-whether we controlled for baseline BDI-II or not. To help clarify this discrepancy, we therefore further explored specific questions in these questionnaires (with no correction for multiple testing). The Met allele was specifically associated with increased emergence of only a subset of symptoms during IFN- $\alpha$ therapy including suicidal ideation (Q9 of the BDI-II; $\left.F_{4,112.2}=2.5 ; P<0.05\right)$ (Figure 3). Notably, suicidal thoughts were uncommon-only $6.3 \%$ of 

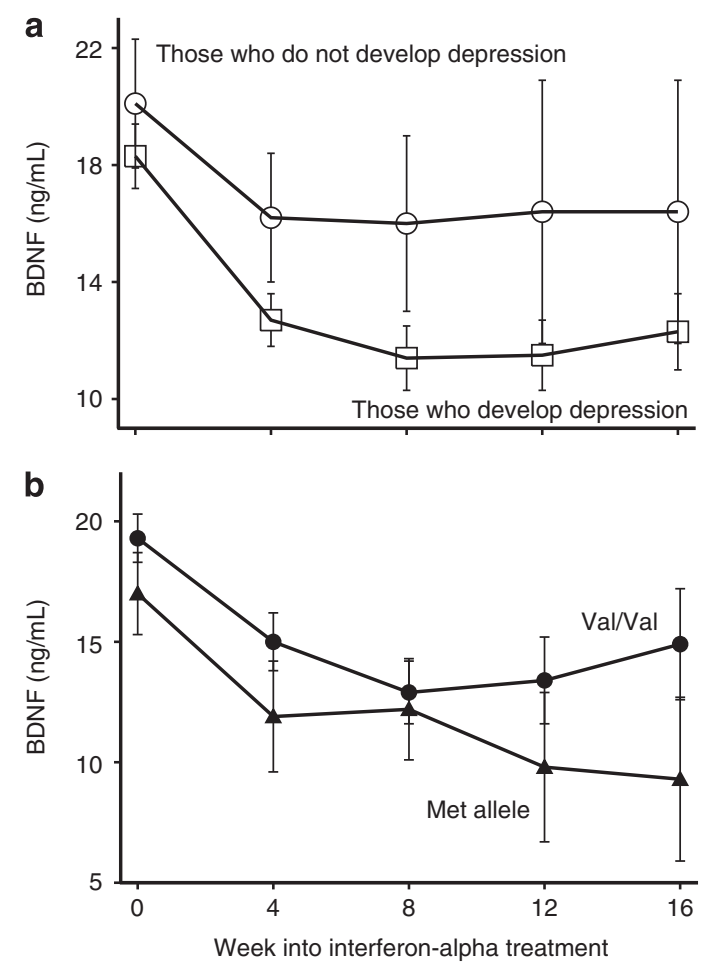

Figure 2 Serum brain-derived neurotrophic factor decreases during IFN- $\alpha$ therapy $\left(F_{4,37.7}=5.0 ; P=0.003\right)$, but similarly whether patients develop MDD (open squares) or not (open circles) $\left(F_{4,47.7}=0.6 ; P=0.6\right)$. Those with the Met allele typically had lower BDNF throughout IFN- $\alpha$ therapy $\left(F_{1,83.0}=5.0 ; P=0.03\right)$, but serum BDNF levels decreased similarly in both genetic groups $(\mathrm{Val} / \mathrm{Val}=$ black circles; Met allele $=$ triangles $)$ over time $\left(F_{4,42.9}=0.3 ; P=0.9\right)$.

people with Met allele and $3.2 \%$ of those with $\mathrm{Val} / \mathrm{Val}$ answered 'I have thoughts of killing myself, but I would not carry them out' on BDI-II question 9 during IFN- $\alpha$ treatment (and there were no suicide attempts by any participants during this study). The Met allele was also associated with increased psychological symptoms on the BDI-II, including sadness $\left(\mathrm{Q} 1 ; \mathrm{F}_{4,21.2}=3.2\right.$; $P=0.03)$, and worthlessness ( $114 ; \mathrm{F}_{4,56.1}=2.7 ; P=0.04$ ) (Figure 3). Conversely, there was no BDNF genetic association with emergence of any neurovegetative symptoms such as insomnia ( $\left.\mathrm{Q} 16 ; \mathrm{F}_{4,47.1}=0.7 ; P=0.6\right)$, fatigue $\left(\mathrm{Q} 20 ; \mathrm{F}_{4,44.2}=0.4 ; \quad P=0.8\right)$, nor appetite (Q18; $\left.\mathrm{F}_{4,39.9}=1.8 ; P=0.14\right)$.

As we have previously found an association between the 5 -HTTLPR polymorphism and risk for MDD during IFN- $\alpha$ treatment (Lotrich et al, 2009), we therefore similarly explored individual BDI-II questions for this polymorphism. During IFN- $\alpha$ therapy, the $S$ allele was associated with the emergence of worsening insomnia $\left(\mathrm{Q} 16 ; \mathrm{F}_{4,24.4}=\right.$ $4.0 ; P=0.01)$ and appetite $\left(\mathrm{Q} 18 ; \mathrm{F}_{4,16.9}=3.2 ; P=0.04\right)$. Fatigue was also worse throughout treatment with IFN- $\alpha$ in those with the $\mathrm{S}$ allele $\left(\mathrm{Q} 20 ; \mathrm{F}_{1,38.2}=4.1 ; P=0.049\right)$, although it worsened equally for both genotypes $\left(\mathrm{F}_{4,25.8}=0.4 ; P=0.8\right)$ (Figure 4). Conversely, there was absolutely no association of the 5-HTTLPR polymorphism and worsening sadness $\left(\mathrm{F}_{4,16.9}=0.1 ; P=0.98\right)$, suicidal thoughts $\left(\mathrm{F}_{4,59.7}=0.5 ; P=0.7\right)$ nor feelings of worthlessness $\left(\mathrm{F}_{4,44.8}=0.2 ; P=0.9\right)$. We also replicated a prior negative finding of no association between 5-HTTLPR and HADS
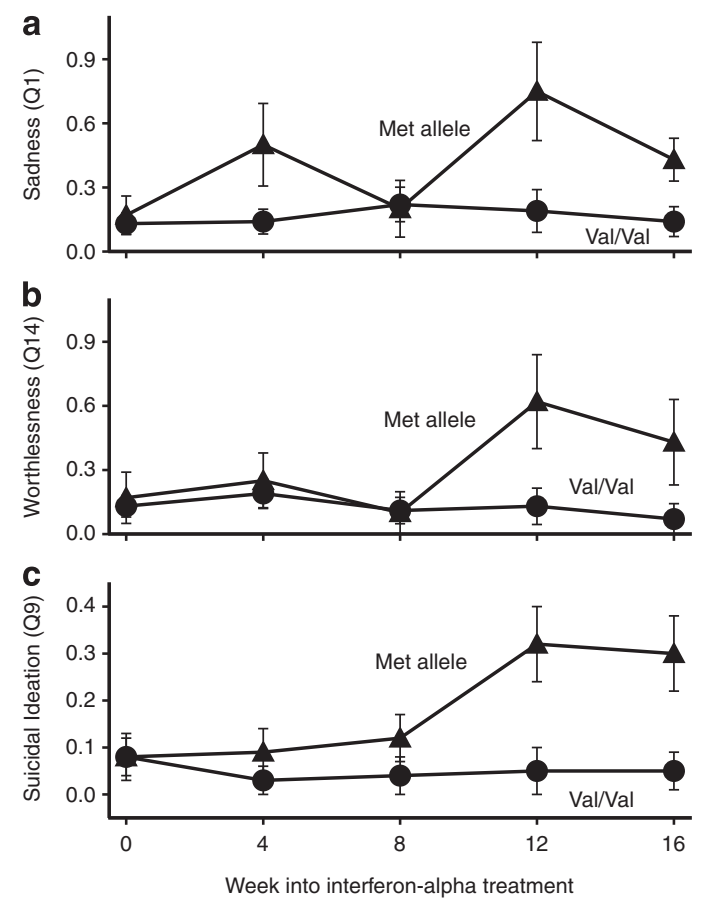

Figure 3 During IFN- $\alpha$ therapy, worsening of psychological symptoms such as 'sadness' (a) and 'worthlessness' (b) increased more in those with the Met allele $\left(F_{4.21 .2}=3.2 ; P=0.03\right.$ and $\left.F_{4.56 .1}=2.7 ; P=0.04\right)$, most prominently by month 3 . Those with the Met allele also had increases in their response to question 9 (c) of the BDI-II regarding suicidal ideation $\left(F_{4,1 \mid 2.2}=2.5 ; P<0.05\right)$

scores during IFN- $\alpha$ treatment (Kraus et al, 2007)—though there was a trend for subjects with the $S$ allele to have greater increase in HADS scores during IFN- $\alpha$ therapy $\left(\mathrm{F}_{4,17.8}=2.6 ; P=0.07\right)$.

As the BDNF Val/Met polymorphism was associated with a subset of depression symptoms, and 5-HTTLPR may be associated with a different cluster of symptoms, we finally explored whether there might be an interaction with 5HTTLPR. We did not observe this (Figure 5). The BDNF Val/Met polymorphism $\left(\mathrm{F}_{4,69.3}=2.7 ; P=0.02\right)$ and 5HTTLPR $\quad\left(\mathrm{F}_{4,69.3}=3.1 ; \quad P=0.01\right) \quad$ were both additively associated with increased depression over time during INF- $\alpha$ therapy, but there was no interaction $\left(\mathrm{F}_{4,69.3}=1.5\right.$; $P=0.21$ ). Those patients with both the $\mathrm{Val} / \mathrm{Val}$ and $\mathrm{L} / \mathrm{L}$ genotype had essentially no worsening of depression symptoms, and those with both the Met allele and S allele had the greatest increase in symptoms (Figure 5).

\section{DISCUSSION}

IFN- $\alpha$ therapy resulted in decreasing BDNF levels along with worsening depression scores, similar to a prior report of 17 patients in the Netherlands (Kenis et al, 2010). In support of a moderator hypothesis, lower BDNF levels prior to IFN- $\alpha$ therapy were predictive of greater depression symptoms during IFN- $\alpha$ treatment, even when controlling for baseline BDI-II scores and sleep quality. However, conclusions regarding a mediator hypothesis were more equivocal. BDNF decreased both in those who developed 

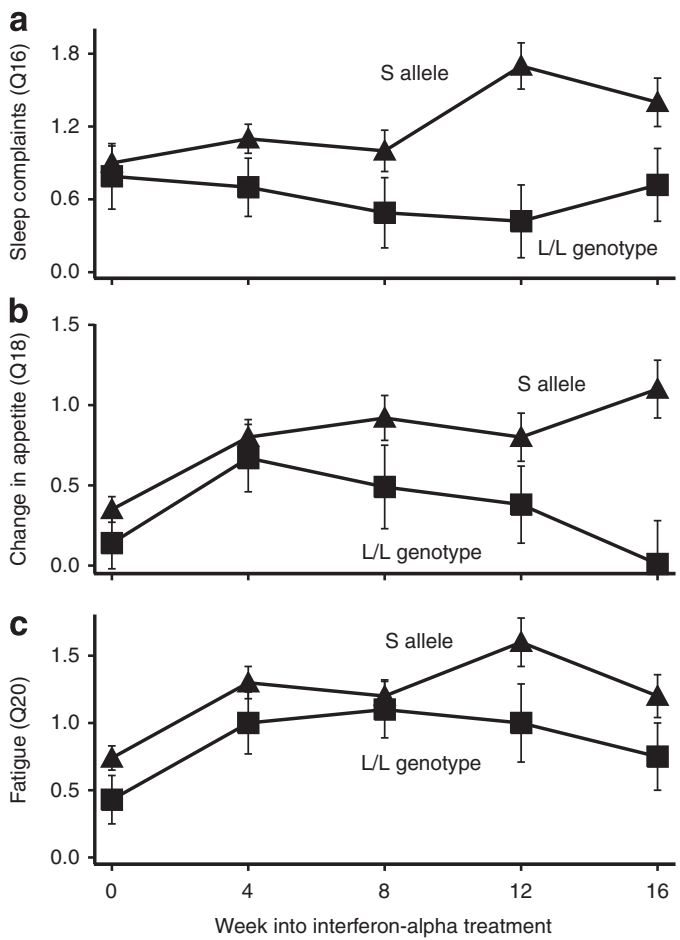

Figure 4 During IFN- $\alpha$ therapy, neurovegetative symptoms such as sleep problems (Panel a. $F_{4,24.4}=4.0 ; P=0.01$ ) and appetite changes (Panel b. $F_{4,16.9}=3.2 ; P=0.04$ ) increased more in those with the Short allele compared to the Long/Long genotype. Those with the Short allele also had worse fatigue throughout treatment (Panel c. $F_{1,38.2}=4.1 ; P=0.049$ ), though both genotypes experienced this side effect.

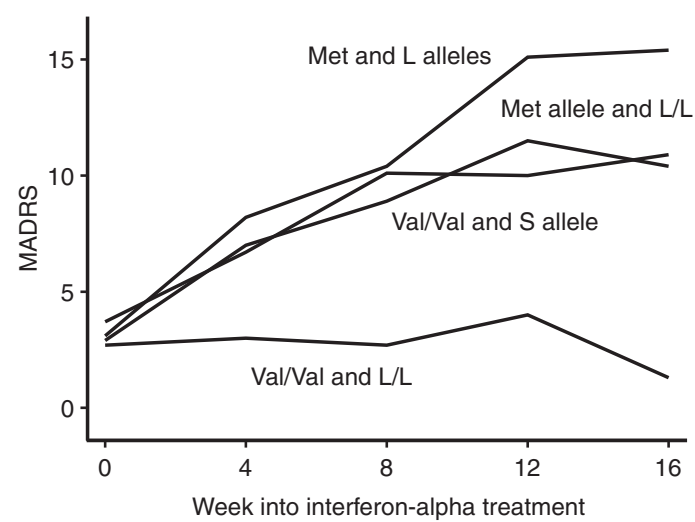

Figure 5 During IFN- $\alpha$ therapy, those with both BDNF Val/Val and 5HTTLPR L/L genotypes had essentially no change in Montgomery-Asperg Depression Rating Scales symptoms, while those with both the Met allele and $\mathrm{S}$ allele had the greatest increase in symptoms.

depression and those who did not-consistent with IFN- $\alpha$ having behavioral effects in rodents without affecting cortical BDNF levels (Fahey et al, 2007).

Other studies also support a moderating effect of BDNF on depression risk. Lower BDNF (and/or the BDNF Met allele) increases risk for depression symptoms in rhesus macaques exposed to early adversity (Kunugi et al, 2010), and in humans exposed to stress (Aguilera et al,

2009; Cirulli et al, 2011; Drachmann et al, 2009), with alcohol dependence (Su et al, 2011) or with Alzheimers disease (Zhang et al, 2011).

There are several plausible pathways by which BDNF could moderate inflammatory cytokine effects. First, inflammation can influence phosphorylation of BDNF's receptor $(\operatorname{TrkB})$, interfering with BDNF signaling (Cortese et al, 2011); and subsequent intracellular signal transduction can be impaired by inflammatory cytokines such as IL-1 (Tong et al, 2008). Both processes could impact depression more in those who start out with low BDNF. Third, BDNF and inflammatory cytokines both influence serotonin transporter transcription and function (Mossner et al, 2000; Mossner et al, 1998; Zhu et al, 2006; Zhu et al, 2010). IFN- $\alpha$ increases serotonin transporter transcription via the MAP kinase intracellular signaling pathway (Tsao et al, 2008), and both BDNF and inflammatory cytokines share overlapping intracellular signal transduction pathways including MAP kinases (Duman et al, 2007; Zhu et al, 2010) and NF-kappaB (Kairisalo et al, 2009). Fourth, the BDNF Met allele has been associated with an elevated cortical response to a dexamethasone/corticosterone releasing hormone challenge (Schule et al, 2006), which is notable given that there is a greater cortical response to the initial injection of IFN- $\alpha$ in those at increased risk for subsequent depression (Raison et al, 2008).

Likely mediated by low BDNF levels, the Met allele was also predictive of depression symptoms. Moreover, similar to prior reports (Kanellopoulos et al, 2011; Pregelj et al, 2011; Sarchiapone et al, 2008), we specifically found that the Met allele was associated with increased suicide ideation, increased sadness, and a sense of worthlessness. The Met allele was not associated with enhanced fatigue, insomnia, or appetite complaints. Thus, how one measures depression may matter for genetic studies.

In fact, different specific depression symptoms may be influenced by different genes (Jang et al, 2004), a phenomenon long noted in mice where different chromosomal regions are implicated in anxiety-depending on what behavioral test is used (Henderson et al, 2004). The possibility that the Met allele is only associated with risk for a subset of symptoms may be one plausible reason that some studies do not replicate an association between depression risk and the BDNF Val/Met polymorphism (Chen et al, 2008; Figueira et al, 2010; Middeldorp et al, 2010; Ribeiro et al, 2007; Suchanek et al, 2011; Wray et al, 2008). There may also be treatment implications. The BDNF Met allele could be associated with better response to SSRIs (Su et al, 2011; Taylor et al, 2011; Zhang et al, 2011), and suicidal ideation is the least common residual symptom following SSRI treatment (McClintock et al, 2011).

Conversely for the 5-HTTLPR insertion/deletion polymorphism, the $S$ allele was specifically associated with increased fatigue, insomnia, and appetite complaints during IFN- $\alpha$ therapy - but not with suicidal ideation, sadness, or worthlessness. Consistent with this, we replicated a prior negative finding that the $S$ allele was not strongly associated with increased HADS scores during IFN $-\alpha$ treatment (Kraus et al, 2007), despite being associated with categorical DSMIV-defined MDD (Bull et al, 2008; Lotrich et al, 2009). This may have treatment implications-(i) emergent neurovegetative symptoms during IFN- $\alpha$ therapy are less responsive to 
SSRI treatment (Capuron et al, 2002); (ii) neurovegetative symptoms are less response to SSRI treatment of MDD in general (McClintock et al, 2011; Morrow et al, 2003; Nierenberg et al, 2010; Targum and Fava, 2011); and (iii)the $S$ allele (which increases risk for neurovegetative symptoms) has been associated with a poor response to SSRI treatment (Lotrich et al, 2008; Porcelli et al, 2012).

Finally, we found that the effects of the two polymorphisms examined were additive, consistent with the nonoverlapping influence on specific depression symptoms. Those who had both risk alleles (the Met and the 5-HTTLPR $S$ alleles) had the greatest increase in total symptoms, whereas those with the two resilient genotypes (Val/Val and $\mathrm{L} / \mathrm{L}$ ) had essentially no increase in symptoms. This latter finding is exploratory and will need to be replicated.

One limitation to these findings is that generalization is minimized by studying resilient subjects who were not depressed despite their chronic hepatitis $\mathrm{C}$ infection. A second caveat is that conclusions are limited by the use of a single homogeneous inflammatory cytokine, IFN- $\alpha$. Thirdly, we did not directly assess cortical BDNF. Given that IFN- $\alpha$ therapy is associated with higher IL- 6 in those who develop MDD (Prather et al, 2009) and IL-6 can induce lymphocytes to increase BDNF production (Kunz et al, 2009), the parsimonious explanation for lowering serum BDNF during IFN- $\alpha$ therapy is that it is a consequence of decreased CNS BDNF (rather than decreased peripheral synthesis) (Lisak et al, 2007). In support of this, BDNF can readily cross the blood-brain barrier via a high-capacity transport system (Pan et al, 1998; Poduslo and Curran, 1996), serum BDNF correlates with cortical BDNF mRNA expression (Gervasoni et al, 2005), and serum BDNF may be affected by changes in cortical BDNF. For example, electroconvulsive treatments result in increased cortical BDNF followed by a rise in serum BDNF (Sartorius et al, 2009).

However, many immune and vascular endothelial cells also produce BNDF (Besser and Wank, 1999; Furuno and Nakanishi, 2006; Kerschensteiner et al, 1999; Kimata, 2005; Nakahashi et al, 2000; Prakash et al, 2009; Rezaee et al, 2010; Ziemssen et al, 2002); serum BDNF also correlates with leukocyte BDNF mRNA (Cattaneo et al, 2009), and systemic levels of BDNF are actually increased during attacks of multiple sclerosis (Liguori et al, 2009). Thus, there may be a complicated relationship between cortical and serum BDNF (Gass and Hellweg, 2010).

Regardless, accruing data indicate a critical role of BDNF and neuroplasticity in the vulnerability to depression (Calabrese et al, 2009; Castren et al, 2010; Sen et al, 2008); many instances of depression are strongly linked with increased inflammatory cytokines (Haroon et al, 2012; Miller et al, 2009), and there is a likely interaction between BDNF and inflammatory cytokines (Lotrich, 2012). Herein, we report that lower BDNF levels (and the Val/Met polymorphisms rs6265) can increase susceptibility to subsequent inflammatory cytokine-associated depression. Rs6265, which is associated with lower BDNF levels, appears to act in conjunction with 5-HTTLPR to increase the risk of total depression symptoms whereby each polymorphism may be influential on distinct sets of depression symptoms. Both BDNF and 5-HT are therefore viable targets for improving resiliency against developing inflammatory cytokine-associated depression.

\section{ACKNOWLEDGEMENTS}

This study was funded by NIMH grants R01MH090250 and P30MH090333.

\section{DISCLOSURE}

The authors declare no conflict of interest.

\section{REFERENCES}

Aguilera M, Arias B, Wichers M, Barrantes-Vidal N, Moya J, Villa H et al (2009). Early adversity and 5-HTT/BDNF genes: new evidence of gene-environment interactions on depressive symptoms in a general population. Psychol Med 39: 1425-1432.

Anisman H (2009). Cascading effects of stressors and inflammatory immune system activation: implications for major depressive disorder. J Psychiatry Neurosci 34: 4-20.

Aydemir C, Yalcin ES, Aksaray S, Kisa C, Yildirim SG, Uzbay T et al (2006). Brain-derived neurotrophic factor (BDNF) changes in the serum of depressed women. Progr Neuropsychopharmacol Biol Psychiatry 30: 1256-1260.

Barrientos RM, Sprunger DB, Campeau S, Higgins EA, Watkins LR, Rudy JW et al (2003). Brain-derived neurotrophic factor mRNA downregulation produced by social isolation is blocked by intrahippocampal interleukin-1 receptor antagonist. Neuroscience 121: 847-853.

Beck A, Steer R, Garbin M (1988). Psychometric properties of the Beck Depression Inventory: twenty-five years of evaluation. Clin Psych Rev 8: 77-100.

Beevers CG, Wells TT, McGeary JE (2009). The BDNF Val66Met polymorphism is associated with rumination in healthy adults. Emotion 9: 579-584.

Ben Menachem-Zidon O, Goshen I, Kreisel T, Ben Menahem T, Reinhartz E, Ben Hur $\mathrm{T}$ et al (2008). Intrahippocampal transplantation of transgenic neural precursor cells overexpressing interleukin-1 receptor antagonist blocks chronic isolationinduced impairment in memory and neurogenesis. Neuropsychopharmacology 33: 2251-2262.

Besser M, Wank R (1999). Cutting edge: clonally restricted production of the neurotrophins brain-derived neurotrophic factor and neurotrophin-3 mRNA by human immune cells and Th1/Th2-polarized expression of their receptors. J Immunol 162: 6303-6306.

Bocchio-Chiavetto L, Zanardini R, Bortolomasi M, Abate M, Segala $\mathrm{M}$, Giacopuzzi M et al (2006). Electroconvulsive therapy (ECT) increases serum brain derived neurotrophic factor (BDNF) in drug resistant depressed patients. Eur Neuropsychopharmacol 16: 620-624.

Borroni B, Grassi M, Archetti S, Costanzi C, Bianchi M, Caim L et al (2009). BDNF genetic variations increase the risk of Alzheimer's disease-related depression. J Alzheimers Dis 8: 867-875.

Bull SJ, Huezo-Diaz P, Binder EB, Cubells JF, Ranjith G, Maddock C et al (2008). Functional polymorphisms in the interleukin-6 and serotonin transporter genes, and depression and fatigue induced by interferon-a and ribavirin treatment. Mol Psychiatry 14: 1095-1104.

Calabrese F, Molteni R, Racagni G, Riva MA (2009). Neuronal plasticity: a link between stress and mood disorders. Psychoneuroendocrinology 34(Suppl 1): S208-S216.

Capuron L, Gumnick JF, Musselman DL, Lawson DH, Reemsnyder A, Nemeroff CB et al (2002). Neurobehavioral effects of interferon-a in cancer patients: phenomenology and paroxetine responsiveness of symptom dimensions. Neuropsychopharmacology 26: 643-652. 
Castren E, Rantamaki T (2010). The role of BDNF and its receptors in depression and antidepressant drug action: reactivation of developmental plasticity. Dev Neurobiol 70: 289-297.

Cattaneo A, Bocchio-Chiavetto L, Zanardini R, Milanesi E, Placentino A, Gennarelli M (2009). Reduced peripheral brainderived neurotrophic factor mRNA levels are normalized by antidepressant treatment. Int J Neuropsychopharmacol 13: 103-108.

Chen B, Dowlatshahi D, MacQueen GM, Wang JF, Young LT (2001). Increased hippocampal BDNF immunoreactivity in subjects treated with antidepressant medication. Biol Psychiatry 50: $260-265$.

Chen L, Lawlor DA, Lewis SJ, Yuan W, Abdollahi MR, Timpson NJ et al (2008). Genetic association study of BDNF in depression: finding from two cohort studies and a meta-analysis. Am J Med Genet B Neuropsychiatr Genet 147B: 814-821.

Choi S-W, GBhang S, Ahn J-H (2011). Diurnal variation and gender differences of plasma brain-derived neurotrophic factor in healthy human subjects. Psychiatry Res 186: 427-430.

Cirulli F, Reif A, Herterich S, Lesch KP, Berry A, Francia N et al (2011). A novel BDNF polymorphism affects plasma protein levels in interaction with early adversity in rhesus macaques. Psychoneuroendocrinology 36: 382-379.

Cortese GP, Barrientos RM, Maier SF, Patterson SL (2011). Aging and a peripheral immune challenge interact to reduce mature brain-derived neurotrophic factor and activation of TrkB, PLCgamma1, and ERK in hippocampal synaptoneurosomes. J Neurosci 31: 4274-4279.

Dantzer R, O'Connor JC, Freund GG, Johnson RW, Kelley KW (2008). From inflammation to sickness and depression: when the immune system subjugates the brain. Nat Rev Neurosci 9: 46-56.

Drachmann BJ, Bock C, Vinberg M, Werg eT, Gether U, Vedel Kessing L (2009). Interaction between genetic polymorphisms and stressful life events in first episode depression. J Affect Disorder 119: 107-115.

Duman CH, Schlesinger L, Kodama M, Russel DS, Duman RS (2007). A role for MAP kinase signaling in behavioral models of depression and antidepressant treatment. Biol Psychiatry 61: 661-670.

Duman RS, Monteggia LM (2006). A neurotrophic model for stress-related mood disorders. Biol Psychiatry 59: 1116-1127.

Duncan LE, Hutchison KE, Carey G, Craighead WE (2009). Variation in brain-derived neurotrophic factor (BDNF) gene is associated with symptoms of depression. J Affect Disorder 115: 215-219.

Egan MF, Kojima M, Callicott JH, Goldberg TE, Kolachana BS, Bertolino A et al (2003). The BDNF val66met polymorphism affects activity-dependent secretion of BDNF and human memory and hippocampal function. Cell 112: 257-269.

Evans DL, Charney DS, Lewis L, Golden RN, Gorman JM, Krishnan KR et al (2005). Mood disorders in the medically ill: scientific review and recommendations. Biol Psychiatry 58: 175-189.

Fahey B, Hickey B, Kelleher D, O'Dwyer AM, O’Mara SM (2007). The widely-used anti-viral drug interferon-alpha induces depressive- and anxiogenic-like effects in healthy rats. Behav Brain Res 182: 80-87.

Felger JC, Alagbe O, Hu F, Mook D, Freeman AA, Sanchez MM et al (2007). Effects of interferon-alpha on rhesus monkeys: a nonhuman primate model of cytokine-induced depression. Biol Psychiatry 62: 1324-1333.

Felger JC, Alagbe O, Pace TWW, Woolwine BJ, Hu F, Raison CL et al (2011). Early activation of p38 mitogen activated protein kinase is associated with interferon-alpha-induced depression and fatigue. Brain Behav Immun 25: 1094-1098.

Figueira P, Malloy-Diniz L, Campos SB, Miranda DM, RomanoSilva MA, De Marco L et al (2010). An association study between the Val66Met polymorphism of the BDNF gene and postpartum depression. Arch Womens Ment Health 13: 285-289.
Foley DL, Neale MC, Gardner CO, Pickles A,SKK (2003). Major depression and associated impairment: same or different genetic and environmental risk factors? Am J Psychiatry 160: 2128-2133.

Franzen PL, Buysse DJ, Rabinovitz M, Pollock BG, Lotrich FE (2009). Poor sleep quality predicts onset of either major depression or subsyndromal depression with irritability during interferon-alpha treatment. J Psychiatr Res 177: 240-245.

Furuno T, Nakanishi M (2006). Neurotrophic factors increase tumor necrosis factor-alpha-induced nuclear translocation of NF-kappaB in rat PC12 cells. Neurosci Letters 392: 240-244.

Gass P, Hellweg R (2010). Peripheral brain-derived neurotrophic factor (BDNF) as a biomarker for affective disorders? Int $J$ Neuropsychopharmacol 13: 1-4.

Gatt JM, Kuan SA, Dobson-Stone C, Paul RH, Joffe RT, Kemp AH et al (2008). Association between BDNF Val66Met polymorphism and trait depression is mediated via resting EEG alpha band activity. Biol Psychology 79: 275-284.

Gatt JM, Nemeroff CB, Schofield PR, Paul RH, Clark CR, Gordon E et al (2010). Early life stress combined with serotonin $3 \mathrm{~A}$ receptor and brain-derived neurotrophic factor valine 66 to methionine genotypes impacts emotional brain and arousal correlates of risk for depression. Biol Psychiatry 68: 818-824.

Gervasoni N, Aubry JM, Bondolfi G, Osiek C, Schwald M, Bertschy $\mathrm{G}$ et al (2005). Partial normalization of serum brain-derived neurotrophic factor in remitted patients after a major depressive episode. Neuropsychobiology 51: 234-238.

Goldstein B, Collinger KA, Lotrich FE, Marsland AL, Gill M-K, Axelson DA et al (2011). Preliminary findings regarding proinflammatory markers and brain-derived neurotrophic factor among adolescents with bipolar spectrum disorders. J Child Adolesc Psychopharmacol 1: 479-484.

Guan Z, Fang J (2006). Peripheral immune activation by lipopolysaccharide decreases neurotrophins in the cortex and hippocampus in rats. Brain Behav Immun 20: 64-71.

Haroon E, Raison CL, Miller AH (2012). Psychoneuroimmunology meets neuropsychopharmacology: translational implications of the impact of inflammation on behavior. Neuropsychopharmacology 37: 137-162.

Hashimoto K (2010). Brain-derived neurotrophic factor as a biomarker for mood disorders: an historical overview and future directions. Psychiatry Clin Neurosci 64: 341-357.

Hayden EP, Klein DN, Dougherty LR, Olino TM, Dyson MW, Durbin CE et al (2010). The role of brain-derived neurotrophic factor genotype, parental depression, and relationship discord in predicting early-emerging negative emotionality. Psychol Sci 21: $1678-1685$

Henderson ND, Turri MG, DeFries JC, Flint J (2004). QTL analysis of multiple behavioral measures of anxiety in mice. Behav Genet 34: $267-293$

Jang KL, Livesley WJ, Taylor S, Stein MB, Moon EC (2004). Heritability of individual depressive symptoms. J Affect Disord 80: $125-133$.

Jen JF, Glue P, Ezzet F, Chung C, Gupta SK, Jacobs S et al (2001). Population pharmacokinetic analysis of pegylated interferon alfa- $2 \mathrm{~b}$ and interferon alfa- $2 \mathrm{~b}$ in patients with chronic hepatitis C. Clin Pharmacol Ther 69: 407-421.

Jiang X, Xu K, Hoberman J, Tian F, Marko AJ, Waheed JF et al (2005). BDNF variation and mood disorders: a novel functional promoter polymorphism and Val66Met are associated with anxiety but have opposing effects. Neuropsychopharmacology 30 1353-1361.

Kairisalo M, Korhonen L, Sepp M, Pruunsild P, Kukkonen JP, Kivinen J et al (2009). NF-kappaB-dependent regulation of brain-derived neurotrophic factor in hippocampal neurons by X-linked inhibitor of apoptosis protein. Eur J Neurosci 30: 958-966.

Kaneko N, Kudo K, Mabuchi T, Takemoto K, Fujimaki K, Wati H et al (2006). Suppression of cell proliferation by interferon-alpha 
through interleukin-1 production in adult rat dentate gyrus. Neuropsychopharmacology 1: 2619-2626.

Kanellopoulos D, Gunning FM, Morimoto SS, Hoptman MJ, Murphy CF, Kelly RE et al (2011). Hippocampal volumes and the brain-derived neurotrophic factor val66met polymorphism in geriatric major depression. Am J Geriatr Psychiatry 19: 13-22.

Kenis G, Prickaerts J, van Os J, Koek GH, Robaeys G, Steinbusch HWM et al (2010). Depressive symptoms following interferon- $\alpha$ therapy: mediated by immune-induced reductions in brainderived neurotrophic factor? Int J Neuropsychopharmacol 14: 247-253.

Kerschensteiner M, Gallmeier E, Behrens L, Leal V, Misgeld T, Klinkert WE et al (1999). Activated human T cells, B cells, and monocytes produce brain-derived neurotrophic factor in vitro and in inflammatory brain lesions: a neuroprotective role of inflammation? J Exp Med 189: 865-870.

Kim JM, Stewart R, Kim SW, Yang SJ, Shin IS, Kim YH et al (2008). BDNF genotype potentially modifying the association between incident stroke and depression. Neurobiol Aging 29: 789-792.

Kimata H (2005). Brain-derived neurotrophic factor selectively enhances allergen-specific IgE production. Neuropeptides 39: 379-383.

Koo JW, Duman RS (2008). IL-1beta is an essential mediator of the antineurogenic and anhedondic effects of stress. PNAS 105: 751-756.

Koo JW, Russo SJ, Ferguson D, Nestler NJ, Duman RS (2010). Nuclear factor-kb is a critical mediator of stress-impaired neurogenesis and depressive behavior. PNAS 107: 2669-2674.

Kraus MR, Al-Taie O, Schefer A, Pfersdorff M, Lesch KP, Scheurlen $M$ (2007). Serotonin-1A receptor gene (HTR1A) vairation predicts interferon-induced depression chronic hepatitis C. Gastroenterology 132: 1279-1286.

Kunugi H, Hor $\mathrm{iH}$, Adachi N, Numakawa T (2010). Interface between hypothalamic-pituitary-adrenal axis and brain-derived neurotrophic factor in depression. Psychiatry Clin Neurosci 64: 477-459.

Kunz D, Walker G, Bedoucha M, Certa U, Marz-Weiss P, Dimitriades-Schmutz B et al (2009). Expression profiling and ingenuity biological function analyses of interleukin-6versus nerve growth factor-stimulated PC12 cells. BMC Genomics 10: 90 .

Lau JY, Goldman D, Buzas B, Hodgkinson C, Leibenluft E, Nelson E et al (2010). BDNF gene polymorphism (Val66Met) predicts amygdala and anterior hippocampus responses to emotional faces in anxious and depressed adolescents. Neuroimage 53: 952-961.

Lavebratt C, Aberg E, Sjoholm LK, Forsell Y (2010). Variations in FKBP5 and BDNF genes are suggestively associated with depression in a Swedish population-based cohort. J Affect Disord 125: 249-255.

Liguori M, Fera F, Patitucci A, Manna I, Condino F, Valentino P et al (2009). A longitudinal observation of brain-derived neurotrophic factor mRNA levels in patients with relapsingremitting multiple sclerosis. Brain Res 1256: 123-128.

Lisak RP, Benjamins J, Bealmear B, Nedelkoska L, Yao B, Land S et al (2007). Differential effects of Th1, monocyte/macrophage and Th2 cytokine mixtures on early gene expression for glial and neural-related molecules in central nervous system mixed glial cell cultures: neurotrophins, growth factors and structural proteins. J Neuroinflammation 4: 30.

Lotrich FE (2009). Risk factors and prevention of interferoninduced depression. Dialogues Clin Neurosci 11: 417-426.

Lotrich FE (2011). Gene-environment interactions in geriatric depression. Psychiatr Clin North Am 34: 357-376.

Lotrich FE (2012). Inflammatory cytokines, growth factors, and depression. Curr Pharm Des 18: 5920-5935.

Lotrich FE, Ferrell RE, Rabinovitz M, Pollock BG (2009). Risk for depression during interferon-alpha treatment is affected by the serotonin transporter polymorphism. Biol Psychiatry 65: 344-348.

Lotrich FE, Ferrell RF, Rabinovitz M, Pollock BG (2010). Labile anger during interferon-alpha treatment is associated with a polymorphism in tumor necrosis factor-alpha. Clin Neuropharmacol 33: 191-197.

Lotrich FE, Loftis JM, Ferrell RE, Rabinovitz M, Hauser P (2011). IL28B polymorphism is associated with both side effects and clearance of hepatitis C during interferon-alpha therapy. J Interferon Cytokine Res 31: 331-336.

Lotrich FE, Pollock BG, Kirshner M, Ferrell RF, Reynolds CR (2008). Serotonin transporter genotype interacts with paroxetine plasma levels to influence depression treatment response. J Psychiatry Neurosci 33: 123-130.

Lotrich FE, Rabinovitz F, Gironda P, Pollock BG (2007). Depression following pegylated interferon-alpha: characteristics and vulnerability. J Psychosomat Res 63: 131-135.

Lotrich FE, Sears B, McNamara R (2012). Elevated ratio of arachidonic acid to long-chain omega-3 fatty acids predicts depression development following interferon-alpha treatment: relationship with interleukin-6. Brain Behav Immun epub ahead of print doi:10.1016/j.bbi.2012.08.007.

Maes M (2011). Depression is an inflammatory disease, but cellmediated immune activation is the key component of depression. Prog Neuropsychopharmacol Biol Psychiatry 35: 664-675.

McClintock SM, Husain MM, Wisniewski SR, Nierenberg AA, Stewart JW, Trivedi MH et al (2011). Residual symptoms in depressed outpatients who respond by $50 \%$ but do not remit to antidepressant medication. J Clin Psychopharmacol 31: 180-186.

Middeldorp CM, Slof-Op 't Landt MC, Medland SE, van Beijsterveldt CE, Bartels M, Willemsen G et al (2010). Anxiety and depression in children and adults: influence of serotonergic and neurotrophic genes? Genes Brain Behav 9: 808-816.

Miller AH, Maletic V, Raison CL (2009). Inflammation and its discontents: The role of cytokines in the pathophysiology of major depression. Biol Psychiatry 65: 732-741.

Miller MD, Paradis CF, Houck PR, Mazumdar S, Stack JA, Rifai AH et al (1992). Rating chronic medical illness burden in geropsychiatric practice and research: application of the Cumulative Illness Rating Scale. Psychiatry Res 41: 237-248.

Montag C, Basten U, Stelzel C, Fiebach CJ, Reuter M (2010). The BDNF Val66Met polymorphism and anxiety: support for animal knock-in studies from a genetic association study in humans. Psychiatry Res 79: 86-90.

Montag C, Reuter M, Newport B, Elger C, Weber B (2008). The BDNF Val66Met polymorphism affects amygdala activity in response to emotional stimuli: evidence from a genetic imaging study. Neuroimage 42: 1554-1559.

Montag C, Weber B, Fliessbach K, Elger C, Reuter M (2009). The BDNF Val66Met polymorphism impacts parahippocampal and amygdala volume in healthy humans: incremental support for a genetic risk factor for depression. Psycholog Med 39: 1831-1839.

Montgomery SA, Asberg M (1979). A new depression scale designed to be sensitive to change. Br J Psychiatry 134: 382-389.

Morrow GR, Hickock JT, Roscoe JA, Raubertas RF, Andrews PL, Flynn PJ et al (2003). Differential effects of paroxetine on fatigue and depression: a randomized, double-blind trial from the Univeristy of Rochester Cancer Center Community Clinical Oncology Program. J Clin Oncol 21: 4635-4641.

Mossner R, Daniel S, Albert D, Heils A, Okladnova O, Schmitt A et al (2000). Serotonin transporter function is modulated by brain-derived neurotrophic factor (BDNF) but not nerve growth factor (NGF). Neurochem Int 36: 197-202.

Mossner R, Heils A, Stober G, Okladnova O, Daniel S, Lesch KP (1998). Enhancement of serotonin transporter function by tumor necrosis factor alpha but not by interleukin-6. Neurochem Int 33: 251-254. 
Moussavi S, Chatterji S, Verdes E, Tandon A, Patel V, Ustun B (2007). Depression, chronic diseases, and decrements in health: results from the World Health Surveys. Lancet 370: 851-858.

Nakahashi T, Fujimura H, Altar CA, Li J, Kambayashi J, Tandon NN et al (2000). Vascular endothelial cells synthesize and secrete brain-derived neurotrophic factor. FEBS Lett 470: 113-117.

Nierenberg AA, Husain MM, Trivedi MH, Fava M, Warden D, Wisniewski SR et al (2010). Residual symptoms after remission of major depressive disorder with citalopram and risk for relapse: a STAR ${ }^{\star D}$ report. Psychol Med 0: 41-50.

Numakawa T, Suzuki S, Kumamaru E, Adachi N, Richards M, Kunugi $\mathrm{H}$ (2010). BDNF function and intracellular signaling in neurons. Histol Histopathol 25: 237-258.

Ozan E, Okur H, Eker C, Eker OD, Gonul AS, Akarsu N (2010). The effect of depression, BDNF gene val66met polymorphism and gender on serum BDNF levels. Brain Res Bull 1: 61-65.

Pan W, Banks WA, Fasold MB, Bluth J, Kastin AJ (1998). Transport of brain-derived neurotrophic factor across the blood-brain barrier. Neuropharmacology 37: 1553-1561.

Peng CH, Chiou SH, Chen SJ, Chou YC, Ky HH, Cheng CK (2008). Neuroprotection by imipramine against lipopolysaccharideinduced apoptosis in hippocampus-dreived neural stem cellsmediated by activation of BDNF and the MAPK pathway. Eur Neuropsychopharmacol 18: 128-140.

Poduslo JF, Curran GL (1996). Permeability at the blood-brain and blood-nerve barriers of the neurotrophic factors: NGF, CNTF, NT-3, BDNF. Brain Res Mol Brain Res 36: 280-286.

Porcelli S, Fabbri C, Serretti A (2012). Meta-analysis of serotonin transporter gene promoter polymorphism (5-HTTLPR) association with antidepressant efficacy. Eur Neuropsychopharmacol 22: 239-258.

Prakash YS, Thompson MA, Pabelick CM (2009). Brain-derived neurotrophic factor in TNF-alpha modulation of $\mathrm{Ca} 2+$ in human airway smooth muscle. Am J Respir Cell Mol Biol 41: 603-611.

Prather AA, Rabinovitz M, Pollock BG, Lotrich FE (2009). Cytokine-induced depression during IFN- $\alpha$ treatment: the role of IL-6 and sleep quality. Brain Behav Immun 23: 1109-1116.

Pregelj P, Nedic G, Paska AV, Zupanc T, Nikolac M, Balazic J et al (2011). The association between brain-derived neurotrophic factor polymorphism (BDNF Val66Met) and suicide. J Affect Disord 128: 287-290.

Quan N, Banks WA (2007). Brain-immune communication pathways. Brain Behav Immun 21: 727-735.

Raison CL, Borisov AS, Majer M, Drake DF, Pagnoni G, Woolwine BJ et al (2009). Activation of central nervous system inflammatory pathways by interferon-alpha: relationship to monoamines and depression. Biol Psychiatry 65: 296-303.

Raison CL, Borisov AS, Woolwine BJ, Massung B, Vogt G, Miller AH (2008). Interferon-[alpha] effects on diurnal hypothalamic-pituitary-adrenal axis activity: relationship with proinflammatory cytokines and behavior. Mol Psychiatry 15: 535-547.

Raison CL, Borisov AS, Woolwine BJ, Massung B, Vogt GJ, Miller $\mathrm{AH}$ (2010a). Interferon-alpha effects on diurnal hypothalamicpituitary-adrenal axis activity: relationship with proinflammatory cytokines and behavior. Mol Psychiatry 15: 535-547.

Raison CL, Capuron L, Miller AH (2006). Cytokines sing the blues: Inflammation and the pathogenesis of depression. Trends Immunol 27: 24-31.

Raison CL, Dantzer R, Kelley KW, Lawson MA, Woolwine BJ, Vogt GJ et al (2010b). CSF concentrations of brain tryptophan and kynurenines during immune stimulation with IFN-alpha: relationship to CNS immune responses and depression. $\mathrm{Mol}$ Psychiatry 15: 393-403.

Raison CL, Demetrashvili M, Capuron L, Miller AH (2005). Neuropsychiatric adverse effects of interferon-a: recognition and management. CNS Drugs 19: 105-123.
Rezaee F, Rellick SL, Piedimonte G, Akers SM, O’Leary HA, Martin $\mathrm{K}$ et al (2010). Neurotrophins regulate bone marrow stromal cell IL-6 expression through the MAPK pathway. PLoS ONE 5: e9690.

Ribeiro L, Busnello JV, Cantor RM, Whelan F, Whittaker P, Deloukas P et al (2007). The brain-derived neurotrophic factor rs6265 (Val66Met) polymorphism and depression in MexicanAmericans. Neuroreport 18: 1291-1293.

Roth TL, Lubin FD, Funk AJ, Sweatt JD (2009). Lasting epigenetic influence of early-life adversity on the BDNF gene. Biol Psychiatry 65: 760-769.

Saarelainen T, Hendolin P, Lucas G, Koponen E, Sairanen M, MacDonald $\mathrm{E}$ et al (2003). Activation of the trkB neurotrophin receptor is induced by antidepressant drugs and is required for antidepressant-induced behavioral effects. J Neurosci 23: 349-357.

Sarchiapone M, Carli V, Roy A, Iacoviello L, Cuomo C, Latella M et al (2008). Association of polymorphism (Val66Met) of brainderived neurotrophic factor with suicide attempts in depressed patients. Neuropsychobiol 57: 139-145.

Sartorius A, Hellweg R, Litzke J, Vogt M, Dormann C, Vollmayr B et al (2009). Correlations and discrepancies between serum and brain tissue levels of neurotrophins after electroconvulsive treatment in rats. Pharmacopsychiatry 42: 270-276.

Schule C, Zill P, Baghai TC, Eser D, Zwanzger P, Wenig N et al (2006). Brain-derived neurotrophic factor Val66Met polymorphism and dexamethasone/CRH test results in depressed patients. Psychoneuroendocrinology 31: 1019-1025.

Sen S, Duman R, Sanacora G (2008). Serum brain-derived neurotrophic factor, depression, and antidepressant medications: meta-analyses and implications. Biol Psychiatry 64: 527-532.

Shimizu E, Hashimoto K, Okamura N, Koike K, Komatsu N, Kumakiri C et al (2003). Alterations of serum levels of brain-derived neurotrophic factor (BDNF) in depressed patients with or without antidepressants. Biol Psychiatry 54: 70-75.

Su K-P, Huang S-Y, Peng C-Y, Lai H-C, Huang C-L, CHen Y-C et al (2010). Phospholipase A2 and cycloxygenase 2 genes influence the risk of interferon-a-induced depression by regulating polyunsaturated faty acids levels. Biol Psychiatry 67: 550-557.

Su N, Zhang L, Fei F, Hu H, Wang K, Hui H et al (2011). The brainderived neurotrophic factor is associated with alcohol dependence-related depression and antidepressant response. Brain Res 1415: $119-126$.

Suchanek R, Owczarek A, Kowalczyk M, Kucia K, Kowalski J (2011). Association between C-281 A and val66met functional polymorphisms of BDNF gene and risk of recurrent major depressive disorder in Polish population. J Mol Neurosci 43: $524-530$

Targum SD, Fava M (2011). Fatigue as a residual symptom of depression. Innov Clin Neurosci 8: 1040-1043.

Taylor WD, McQuoid DR, Ashley-Koch A, MacFall JR, Bridgers J, Krishnan RR et al (2011). BDNF Val66Met genotype and 6month remission rates in late-life depression. Pharmacogenom J 11: 146-154.

Terracciano A, Martin B, Ansari D, Tanaka T, Ferrucci L, Maudsley $S$ et al (2010). Plasma BDNF concentration, Val66Met genetic variant and depression-related personality traits. Genes Brain Behav 9: 512-218.

Tong L, Balazs R, Soiampornkul R, Thangnipon W, Cotman CW (2008). Interleukin-1 beta impairs brain derived neurotrophic factor-induced signal transduction. Neurobiol Aging 29: $1380-1393$

Trajkovska V, Marcussen AB, Vinberg M, Hartvig P, Aznar S, Knudsen GM (2007). Measurements of brain-derived neurotrophic factor: Methodological aspects and demographical data. Brain Res Bull 73: 143-149.

Tsao C-W, Lin Y-S, Cheng J-T, Lin C-F, Wu H-T, Wu S-R et al (2008). Interferon-alpha-induced serotonin uptake in Jurkat $\mathrm{T}$ 
cells via mitogen-activated protein kinase and transcriptional regulation of the serotonin transporter. J Psychopharmacol 22: 753-760.

Verhagen M, van der Meij A, van Deurzen P, Janzing JG, AriasVasquez A, Buitelaar JK et al (2010). Meta-analysis of the BDNF Val66Met polymorphism in major depressive disorder: effects of gender and ethnicity. Mol Psychiatry 15: 260-271.

Wray NR, James MR, Handoko HY, Dumenil T, Lind PA, Montgomery GW et al (2008). Association study of candidate variants from brain-derived neurotrophic factor and dystrobrevin-binding protein 1 with neuroticism, anxiety, and depression. Psychiatr Genet 18: 219-225.

Zhang L, Fang Y, Zeng Z, Lian Y, Wei J, Zhu H et al (2011). BDNF gene polymorphisms are associated with Alzheimer's diseaserelated depression and antidepressant response. J Alzheimers Dis 26: 523-530.

Zhou Z, Lu T, Xu G, Yue X, Zhu W, Ma M et al (2011). Decreased serum brain-derived neurotrophic factor (BDNF) is associated with post-stroke depression but not with BDNF gene Val66Met polymorphism. Clin Chem Lab Med 49: 185-189.

Zhu C-B, Blakely RD, Hewlett WA (2006). The proinflammatory cytokines interleukin-1beta and tumor necrosis factor-alpha activate serotonin transporters. Neuropsychopharmacology 31: 2121-2131.

Zhu CB, Lindler KM, Owens AW, Daws LC, Blakely RD, Hewlett WA (2010). Interleukin-1 receptor activation by systemic lipopolysaccharide induces behavioral despair linked to MAPK regulation of CNS serotonin transporters. Neuropsychopharmacology 35: 2510-2520.

Ziemssen T, Kumpfel T, Klinkert WE, Neuhaus O, Hohlfeld R (2002). Glatiramer acetate-specific T-helper 1- and 2-type cell lines produce BDNF: implications for multiple sclerosis therapy. Brain-derived neurotrophic factor. Brain 125: 2381-2391.

Zigmond AS, Snaith RP (1983). The Hospital Anxiety and Depression Scale. Acta Psychiatr Scand 67: 361-370. 